\title{
HIGH TEMPERATURE Si-DOPED BN INTERPHASES FOR WOVEN SiC/SiC COMPOSITES
}

\author{
Gregory N. Morscher \\ Ohio Aerospace Institute \\ NASA Glenn Research Center \\ Cleveland, $\mathrm{OH} 44135$ \\ Frances Hurwitz \\ NASA Glenn Research Center \\ Cleveland, $\mathrm{OH} 44135$
}

\author{
Hee Mann Yun \\ Cleveland State University \\ NASA Glenn Research Center \\ Cleveland, $\mathrm{OH} 44135$
}

\begin{abstract}
The hydrolytic stability of high-temperature deposited Si-doped BN has been shown in the past to be superior in comparison to "pure" BN processed at similar or even higher temperatures. This type of material would be very desirable as a $\mathrm{SiC} / \mathrm{SiC}$ composite interphase that is formed by chemical infiltration into multi-ply woven preform. However, due to rapid deposition on the preform outer surface at the high processing temperature, this has proven very difficult. To overcome this issue, single plies of woven fabric were infiltrated with Si-doped BN. Three composite panels of different $\mathrm{SiC}$ fiber types were fabricated with $\mathrm{Si}$-doped $\mathrm{BN}$ interphases including Sylramic, Hi-Nicalon Type S and Sylramic-iBN fiber-types. The latter fiber-type possesses a thin in-situ grown BN layer on the fiber surface. High Si contents $(\sim 7$ to $10 \mathrm{a} / \mathrm{o})$ and low oxygen contents $(<1 \mathrm{a} / \mathrm{o})$ were achieved. All three composite systems demonstrated reasonable debonding and sliding properties. The coated Sylramic fabric and composites were weak due to fiber degradation apparently caused during interphase processing by the formation of TiN crystals on the fiber surface. The Hi-Nicalon Type S composites with Si-doped BN interphase were only slightly weaker than Hi-Nicalon Type S composites with conventional BN when the strength on the load-bearing fibers at failure was compared. On the other hand, the Sylramic-iBN fabric and composites with Si-doped BN showed excellent composite and intermediate temperature stress-rupture properties. Most impressive was the lack of any significant interphase oxidation on the fracture surface of stress-ruptured specimens tested well above matrix cracking at $815^{\circ} \mathrm{C}$.
\end{abstract}

\section{INTRODUCTION}

$\mathrm{SiC}$ fiber reinforced $\mathrm{SiC}$ matrix composites with $\mathrm{BN}$ interphases degrade in strength at intermediate temperatures in $\mathrm{O}_{2}$ and $\mathrm{H}_{2} \mathrm{O}$ containing environments due to the instability of $\mathrm{BN}$ in these environments. Oxidation of $\mathrm{BN}$ and $\mathrm{SiC}$ results in glass formation in between neighboring fibers and matrix, i.e., strongly bonded fibers, causing composite embrittlement [1].

One approach to solve this problem is to have an interphase material that is more stable than conventional $\mathrm{BN}$ in these environments and enables the proper mechanical debonding and sliding properties necessary for strong and tough ceramic matrix composites. Significant improvements in the hydrolytic stability of $\mathrm{BN}$ have been observed for $\mathrm{BN}$ fabricated at higher temperatures $\left(1400\right.$ to $1800^{\circ} \mathrm{C}$ ) [2], which is related to the increased crystallinity of the BN. Even greater hydrolytic stability was observed for chemical vapor deposited Si-doped BN processed at $1400^{\circ} \mathrm{C}[2,4]$. For example, two to three orders of magnitude less weight-loss was measured for

This report is a preprint of an article submitted to a journal for publication. Because of changes that may be made before formal publication, this preprint is made available with the understanding that it will not be cited or reproduced without the permission of the author. 
Si-doped BN compared to "pure" BN processed at $1400^{\circ} \mathrm{C}$ for exposures of $1200^{\circ} \mathrm{C}$ to $1500^{\circ} \mathrm{C}$ in air or pure $\mathrm{O}_{2}$ for various times. Also, interphase recession distances measured from exposed (100 hour at $800^{\circ} \mathrm{C}$ in $7 \% \mathrm{H}_{2} \mathrm{O} / 93 \% \mathrm{O}_{2}$ environment) ends of minicomposites were negligible $(<1 \mu \mathrm{m})$ for $1400^{\circ} \mathrm{C}$ processed $\mathrm{Si}$-doped $\mathrm{BN}$ compared to $\sim 200 \mu \mathrm{m}$ for $1400^{\circ} \mathrm{C}$ processed $\mathrm{BN}$ and $\sim 700$ $\mu \mathrm{m}$ for $1050^{\circ} \mathrm{C}$ processed $\mathrm{BN}$.

One drawback to $1400^{\circ} \mathrm{C}$ deposited $\mathrm{Si}-\mathrm{BN}$ is that the high processing temperature (required for the improvements in hydrolytic stability) does not enable chemical vapor infiltration into woven multi-ply preforms. In the earlier report [4], this was overcome by coating individual tows and testing minicomposites. In this study, individual plies of woven fabric were infiltrated successfully. These were then stacked and fabricated into $\mathrm{SiC} / \mathrm{SiC}$ composites.

\section{EXPERIMENTAL}

$\mathrm{SiC} / \mathrm{SiC}$ composites with three different fiber-types were fabricated using CVI Si-doped $\mathrm{BN}$ and conventional $\mathrm{BN}$ interphases (see Table I), and $\mathrm{SiC}$ matrices formed by the meltinfiltration (MI) process [5]. Individual pieces of fabric $(0.3 \mathrm{~m} \mathrm{x} 1 \mathrm{~m})$ were infiltrated with Si-doped BN (Synterials, Inc. Herdon VA). The coated fabric was then cut into $152 \mathrm{~mm} \times 230 \mathrm{~mm}$ pieces and sent to Honeywell Advanced Composites (Newark, DE) for composite fabrication by MI, which included stacking of plies and infiltration of CVI SiC, SiC particle slurry, and molten Si. Tensile dogbone specimens were then cut from the panels.

Some of the physical properties of the three composite panels are listed in Table I. Also shown are properties of comparable panels fabricated with conventional CVI BN. Since the preforms had to be stacked after Si-doped BN interphase coating prior to CVI infiltration, the composite thickness tended to be larger than that of conventional MI composites, in which the plies are first stacked and then infiltrated with CVI BN to form the interphase. This accounts for the lower volume fraction of fibers of Si-doped BN composites compared to composites with the same fiber architecture fabricated with conventional CVI BN. For SiC/SiC MI composites panel densities typically range from 2.8 to $2.9 \mathrm{~g} / \mathrm{cc}$. The panel densities of the Si-doped BN panels ranged from 2.6 to $2.76 \mathrm{~g} / \mathrm{cc}$.

Table I: Composite Properties

\begin{tabular}{|c|c|c|c|c|}
\hline $\begin{array}{c}\text { Fiber/Interphase } \\
\left(\mathbf{e p c m}^{\mathbf{b}}\right)\end{array}$ & $\begin{array}{c}\mathbf{0}^{\mathbf{0}} \text { Fiber } \\
\text { Volume } \\
\text { Fraction }\end{array}$ & $\begin{array}{c}\text { Panel } \\
\text { Density, g/cc }\end{array}$ & $\begin{array}{c}\text { Elastic } \\
\text { Modulus, GPa }\end{array}$ & $\begin{array}{c}\text { RT Ultimate } \\
\text { Strength, MPa }\end{array}$ \\
\hline SYL*/SiBN (8.7) $^{*}$ (1) & 0.19 & 2.70 & 221 & $219 \pm 13$ \\
\hline SYL/CVI BN (8.7) & 0.20 & 2.84 & 265 & $389 \pm 10$ \\
\hline HNS**/SiBN (7.1) & 0.14 & 2.61 & 211 & $213 \pm 5$ \\
\hline HNS/CVI BN (7.1) & 0.18 & 2.80 & 239 & $304 \pm 10$ \\
\hline SYL-iBN\#/SiBN (6.3) & 0.16 & 2.76 & 287 & $334 \pm 8$ \\
\hline SYL-iBN/CVI BN(6.3) & 0.17 & 2.89 & 265 & $374 \pm 9$ \\
\hline
\end{tabular}

* Sylramic fiber: Dow Corning, Midland MI $\quad$ ** Hi-Nicalon Type S: Nippon Carbon, Tokyo Japan

\# Treated Sylramic to produce in-situ BN on fiber prior to composite fabrication [6]

a SiBN refers to high temperature Si-doped BN infiltrated into individual plies of woven fabric; CVI BN refers to conventional low temperature BN infiltrated into a stacked perform of woven fabric

b Fiber tow ends per $\mathrm{cm}$ in the $0^{\circ}$ and $90^{\circ}$ direction. Eight plies of five-harness satin woven fabric were used for each composite.

Room temperature tensile tests, microstructural observation (SEM) and chemical analysis (Auger spectroscopy, AES) were performed on all three systems for both the coated pieces of fabric and fabricated composites. Elevated temperature $\left(815^{\circ} \mathrm{C}\right)$ stress-rupture testing was performed on the composite system with the highest room temperature strength (SYL-iBN). It 
should be noted that this was the first attempt at processing high temperature Si-doped BN interphase composites and the results therefore should be viewed as preliminary.

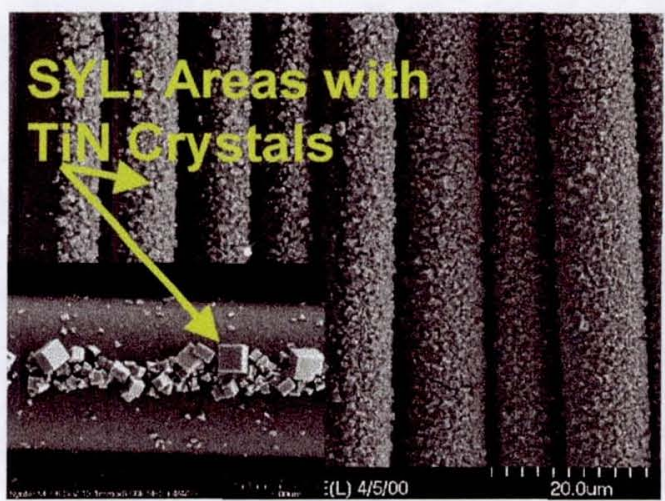

(a)

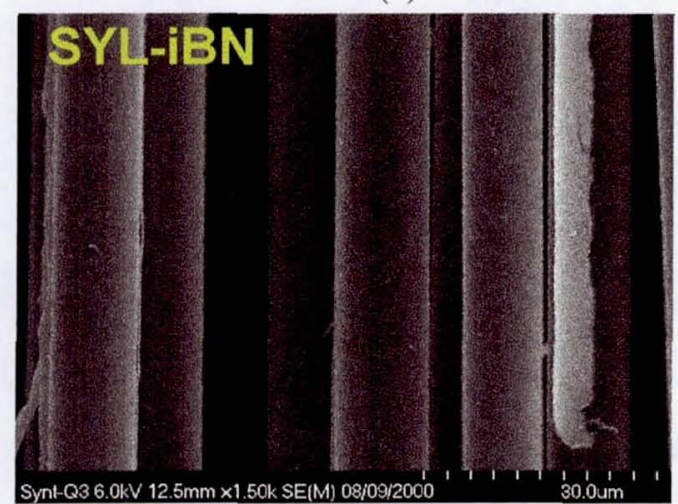

(c)

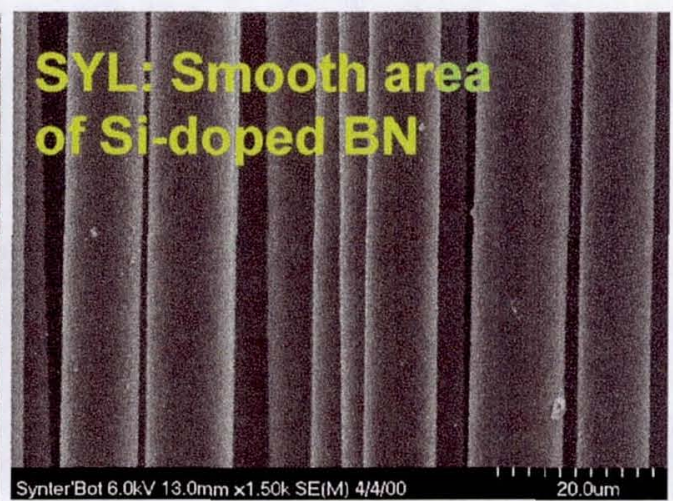

(b)

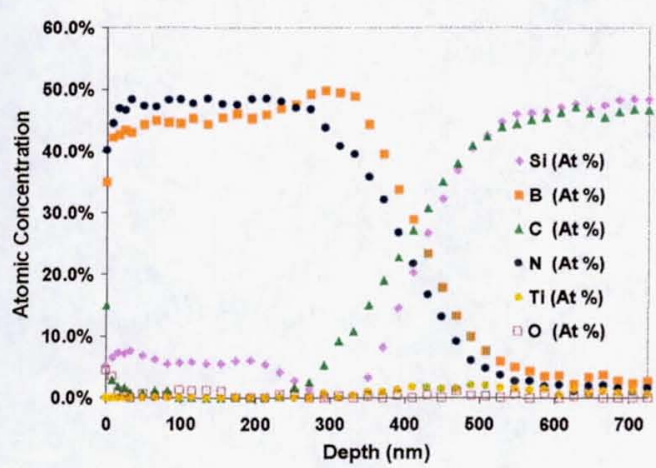

(d)

Figure 1: SEM micrographs of SYL coated cloth (a) with and (b) without TiN deposits. SEM of (c) SYL-iBN cloth and (d) typical AES depth profile of SYL-iBN coated cloth.

\section{RESULTS AND DISCUSSION}

Representative scanning electron micrographs of individual pieces of cloth are shown in Figure 1. Note that for the SYL fabric TiN deposits were observed in some areas. The source of Ti is believed to be the fiber itself [7]. However, regions of good uniformity were attained (Figure 1b), especially for the SYLiBN (Figure 1c) and the HNS fabrics (not shown). Figure 1d shows an AES depth profile from a piece of SYL-iBN cloth. There was very little oxygen in the coating $(<1 \mathrm{a} / \mathrm{o})$, and the content of Si ranged from $\sim 7$ to $10 \mathrm{a} / \mathrm{o}$ for all the coatings.

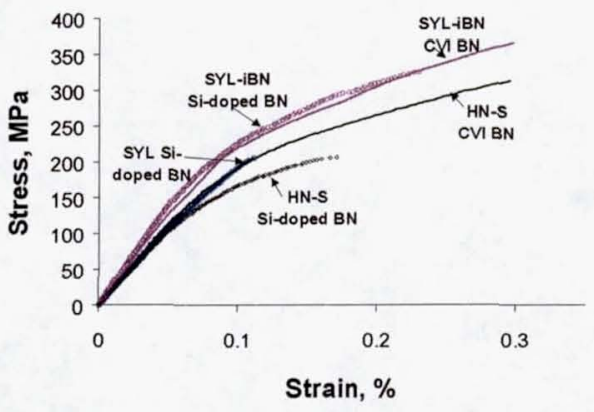

Figure 2: Stress-strain behavior of Si-doped BN and $\mathrm{CVI} \mathrm{BN}$ composites at room temperature. 
The room temperature stress-strain behavior of the composites is shown in Figure 2, with key properties listed in Table I. The fracture surfaces of the three different Si-doped composite types are shown in Figure 3. There was noticeably more porosity for the SYL and HNS composites (Figure $3 \mathrm{~b}$ and $3 \mathrm{c}$ ), which probably accounts for the low elastic modulus values measured for those two composite systems (Table I). Composites fabricated with SYL and SYLiBN fibers typically had fiber pull-out lengths on the order of a fiber diameter and composites fabricated with HNS fibers typically had fiber pull-out lengths on the order of a few fiber diameters. This degree of pull-out behavior is comparable to composites fabricated with conventional CVI-BN for SYL-iBN and HNS that also debond between the fiber and the interphase [8]. The debond interface of the SYL Si-doped BN composites occurred between the

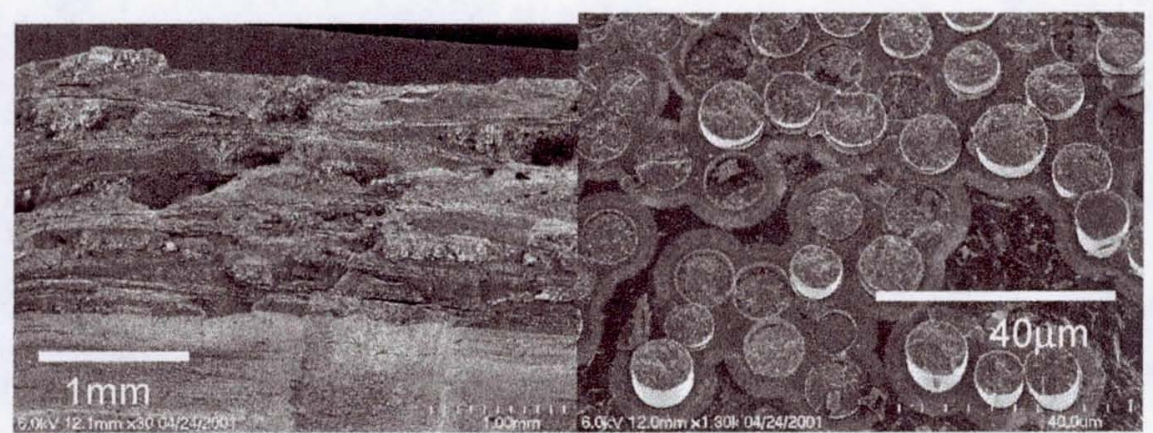

(a)

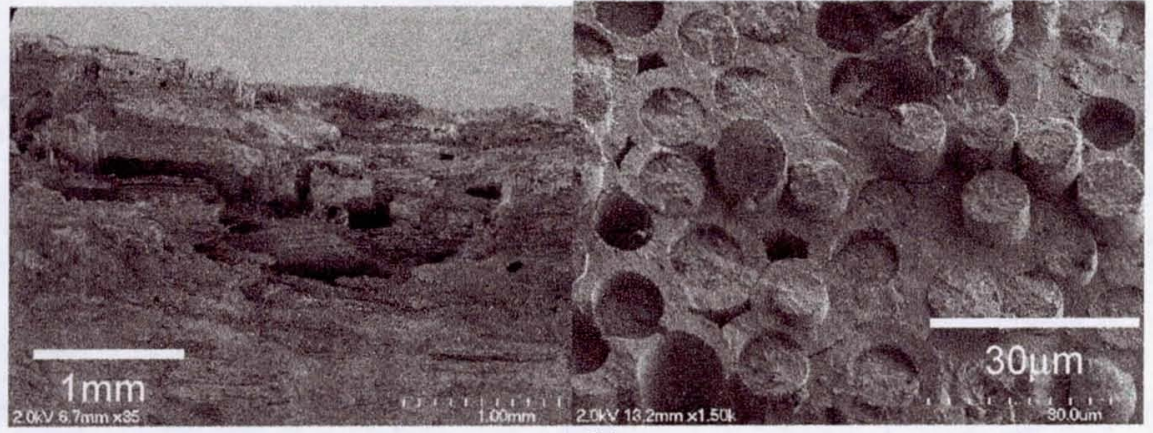

(b)

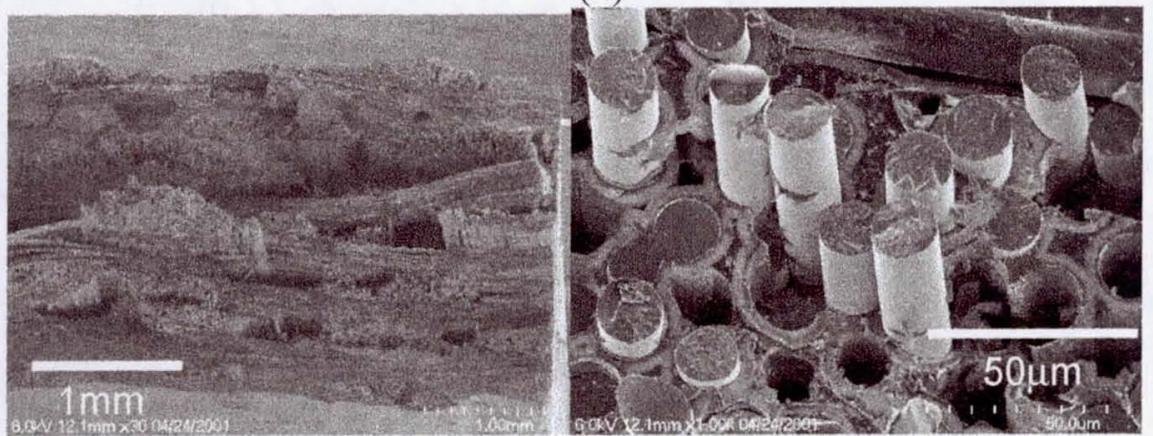

(c)

Figure 3: Lower magnification and higher magnification SEM images of (a) SYL-iBN, (b) SYL, and (c) HN-S composite fracture surfaces. 
Si-doped BN interphase and the matrix, i.e. outside debonding [9]. This composite was fabricated at a different time than the other two composites. Outside debonding has been observed in all three composite systems and usually results in lower interfacial shear strengths and higher strains to failure. The pullout lengths observed for the SYL Si-doped BN composites with outside debonding are significantly smaller than those observed in comparable conventional CVI BN composites with outside debonding [9] which may be indicative of weaker fibers or higher interfacial strengths for the SYL Si-doped composite.

Composites fabricated with conventional CVI BN interphases were considerably stronger than the Si-doped BN interphase composites (Figure 2) [7]. The Si-doped BN composites had lower fractions of fiber compared to composites processed with conventional CVI BN. In order to compare the reinforcing fiber strength in the composites with composites fabricated with conventional CVI BN interphases, the stress on the fibers at failure was determined by dividing the composite failure stress by the fraction of fibers in the loading direction. Figure 4 shows the average fiber stress at failure for the three composite-types with the Si-doped BN and the range of fiber stress at failure for several different composite panels of each fiber-type with conventional $\mathrm{CVI} \mathrm{BN}$ [7]. The failure stress on the fibers for the SYL fibers in Si-doped BN composites were significantly lower than for conventional CVI BN interphase composites. The low composite strength of this system was probably due to fiber weakening, which might correspond with the formation of TiN on the fiber

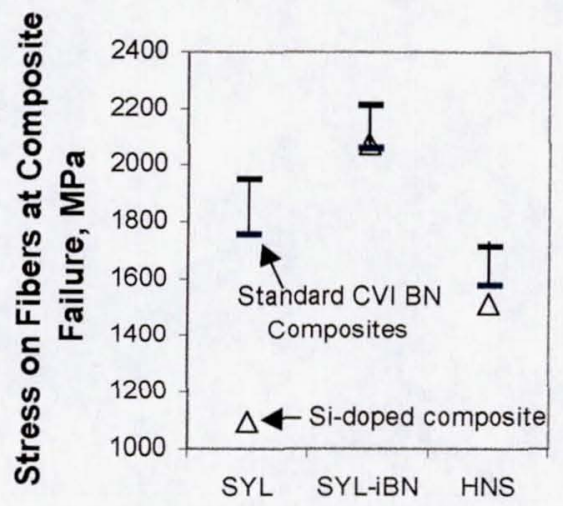
surface. Fibers appear to pullout with ease, i.e. poor composite strengths are not due to strong bonding or high interfacial shear strength. The failure stress on the HN-S fibers in Si-doped BN composites were slightly lower than the range of values obtained from conventional CVI BN composites, which may indicate some strength degradation of this fiber after MI processing. The average failure stress of the SYL-iBN fibers at failure was within the range of fiber strength values obtained for conventional CVI BN composites with SYL-iBN fibers, albeit at the lower end of the range.

The interfacial shear strength was measured for the SYL-iBN composite using a push-in technique [10] and from fitting the stress-strain curves based on the final matrix crack density and the $\mathrm{AE}$ data accumulated during the test (not shown) [11]. Both techniques yielded a value of $80 \mathrm{MPa}$, very similar to that measured for conventional SYL-iBN CVI-BN MI composites $(\sim 70$ $\mathrm{MPa}[11])$. Therefore, the debonding and sliding properties of the Si-doped BN are sufficient for good composite behavior, as was evidenced by the stress-strain curve. Push-in was not performed on the HNS Si-doped BN composite; however, fitting the stress-strain curve based on the estimated stress-dependent crack density yielded an interfacial shear strength value of $\sim 15 \mathrm{MPa}$. The differences in interfacial shear strengths for the two composite systems appear to be consistent based on the differences in observed fiber pullout behavior (Figure 3).

Stress-rupture at $815^{\circ} \mathrm{C}$ in air was performed for the SYL-iBN composites in order to assess the environmental durability of this interphase at intermediate temperatures in the same manner as was described in reference 1 . The $815^{\circ} \mathrm{C}$ stress-rupture of conventional SYL-MI 
composites is shown (Figure 5) for two fabric treatments: as-produced and "fluffed", where the sized fabric was agitated to increase tow widths and reduce fiber-to-fiber contact. Another approach for fiber spreading occurs during formation of the SYL-iBN fibers. Clearly both approaches of fiber spreading are useful for improving rupture life at $815^{\circ} \mathrm{C}$. The rupture of three SYL-iBN Si-doped BN composite specimens gives comparable and sometimes better behavior than the fiberspread composites.

Even though only a modest improvement over the conventional fiber-spread CVI$\mathrm{BN}$ material was observed with Si-doped BN, one drastic microstructual difference was the observation that little oxidation of the interphase had

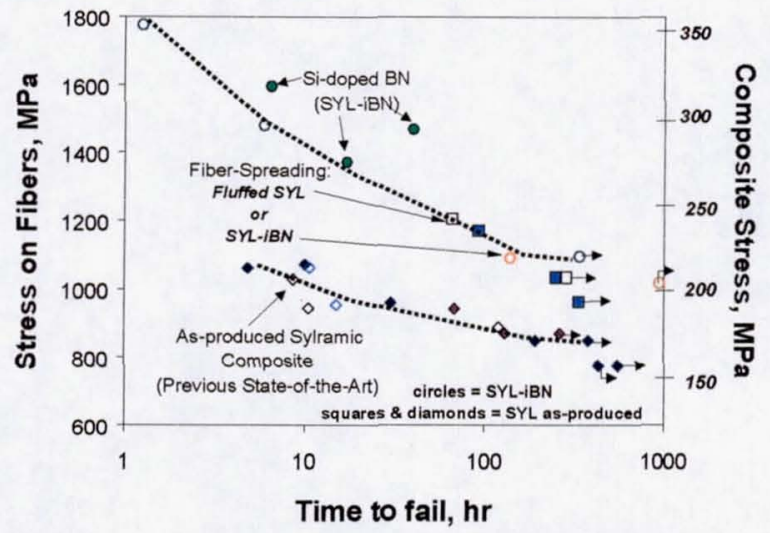

Figure 5: Stress rupture of SYL and SYL-iBN MI composites in air at $815^{\circ} \mathrm{C}$. The composite stress is based on an effective fiber fraction of 0.2 in the stress direction. occurred for specimens subjected to stress-rupture. Figure 6 shows a portion of the fracture surface of a Si-doped BN

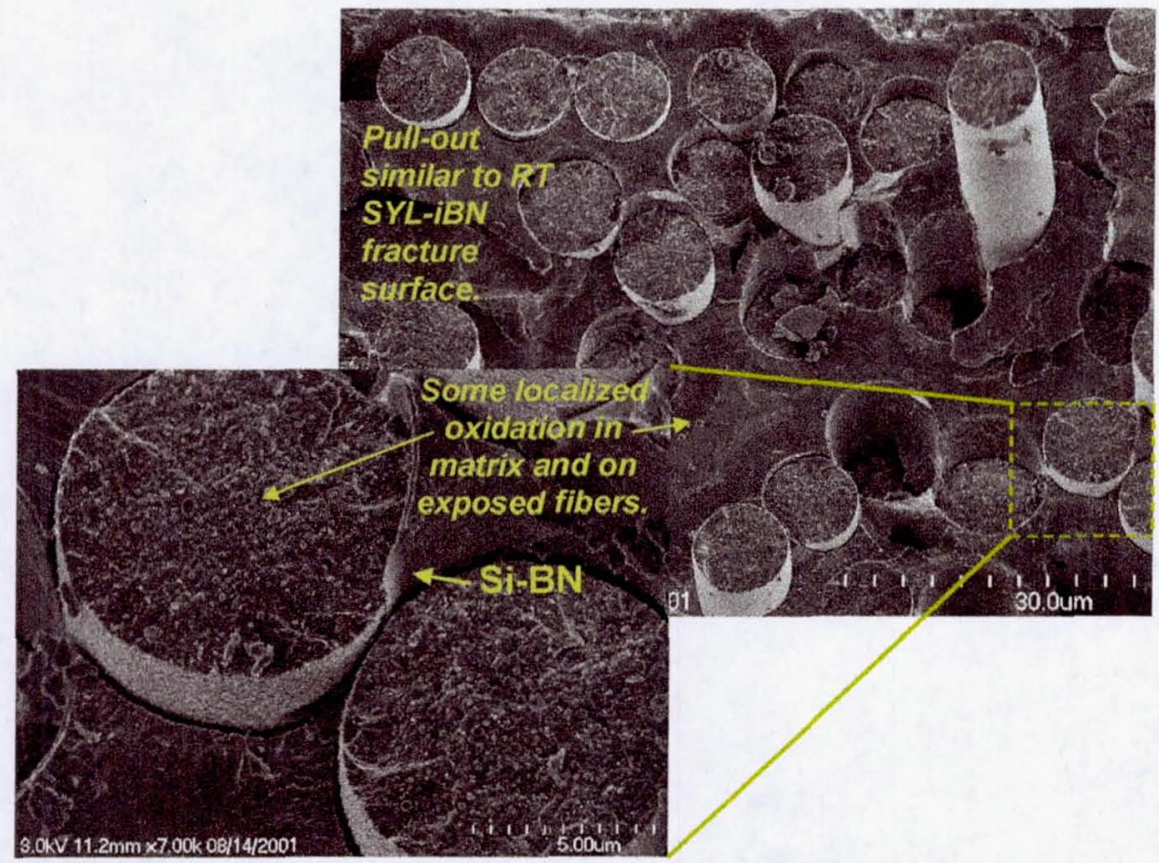

Figure 6: Fracture surface of Si-doped BN MI composite after 40 hours of stress-rupture. The micrographs were taken near the edge of the specimen, i.e. the area where the most oxidation would have taken place. The inner region of the composite showed even less evidence of oxidation. 
SYL-iBN MI composite ruptured after 40 hours. No discernable interphase oxidation and fiber pull-out similar to that of room temperature tested fracture surfaces were evident across the entire fracture surface. The only oxidation that was observed was some oxidation of the fiber fracture surfaces, due to oxidation of B containing species in the fiber, which is present as a sintering aid [7], and local oxidation of the Si portion of the matrix, due to impurities in the Si. The specimen shown in Figure 6 failed overnight and remained in the hot section of the furnace until the following morning. In other words the $\mathrm{Si}$-doped $\mathrm{BN}$ was exposed to the environment for $\sim 55$ hours with little oxidation. For a composite containing conventional CVI BN, after 40 hours stress-rupture in air at $815^{\circ} \mathrm{C}$ (Figure 7), significant oxidation of the interphase had occurred and a thick glass layer had formed over $70 \%$ of the cross-section fusing fibers to one another, resulting in no fiber pull-out and composite embrittlement [12]. This occurred even though the applied stress on the conventional BN composite was $\sim 65 \%$ of that of the Si-doped BN composite (see Figure 5).

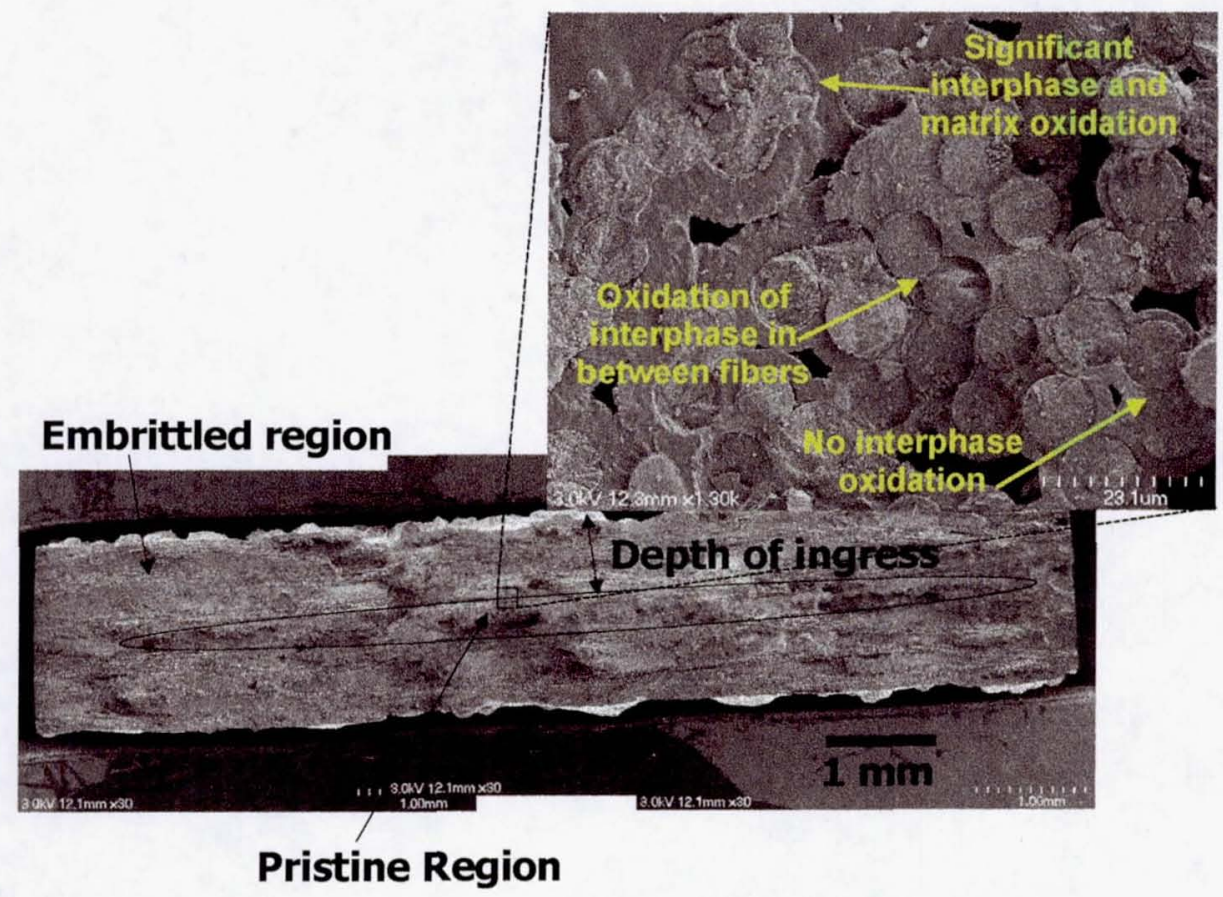

Figure 7: Fracture surface of conventional CVI BN interphase MI composite after 40 hours of stress-rupture. The higher magnification image shows the "oxidation front", i.e., the transition from the completely oxidized region of the matrix crack to the unoxidized interior region of the matrix crack in which composite failure occurred.

\section{CONCLUSIONS}

Si-doped BN interphases deposited at relatively high temperatures on single pieces of fabric were shown to provide the necessary debonding and sliding character for composite interfaces of three different $\mathrm{SiC}$ fiber-type composite systems. Strength degradation occurred for 
the Sylramic composite apparently due to TiN formation during interphase deposition. HN-S and SYL-iBN composites were shown to have reasonable average strength values when the strength of the reinforcing fibers was compared to similar composites fabricated with conventional BN interphases. The intermediate temperature stress-rupture properties of SYL-iBN composites proved to be very good, exceeding the earlier state-of-the-art material with conventional CVI BN interphases. Most impressive was the lack of any significant oxidation at the fracture surface of the Si-doped BN SYL-iBN composite after 40 hours of stress-rupture.

\section{REFERENCES}

1. G.N. Morscher, J. Hurst, and D. Brewer, "Intermediate-Temperature Stress Rupture of a Woven Hi-Nicalon, BN-Interphase, SiC-Matrix Composite in Air," J. Am. Ceram. Soc., 83 [6] 1441-49 (2000)

2. A.W. Moore, H. Sayir, S.C. Farmer, and G.N. Morscher, "Improved Interface Coatings for SiC Fibers in Ceramic Composites," Ceram. Eng. Sci. Proc., 16 [4] 409-416 (1995).

3. C.G. Cofer and J. Economy, "Oxidative and Hydrolytic Stability of Boron Nitride - A New Approach to Improveing the Oxidation Resistance of Carbonaceous Structures," Carbon, 33 [4] 3889-395 (1995)

4. G.N. Morscher, D. Bryant, and R.E. Tressler, "Environmental Durability of BN-Based Interphases (For $\mathrm{SiC}_{\mathrm{f}} / \mathrm{SiC}_{\mathrm{m}}$ Composites) in $\mathrm{H}_{2} \mathrm{O}$ Containing Atmospheres at Intermediate Temperatures," Ceram. Eng. Sci. Proc., 18 [3] 525-533 (1997)

5. D. Brewer, "HSR/EPM Combustor Materials Development Program," Mater. Sci. Eng. A, 261 284-291 (1999).

6. H.M. Yun, J.Z. Gyekenyesi, Y.L. Chen, D.R. Wheeler, and J.A. DiCarlo, "Tensile Behavior of SiC/SiC Composites Reinforced by Treated Sylramic SiC Fibers," Ceram. Eng. Sci. Proc., 22, [3] 521-531. (2001)

7. J. Lipowitz, J.A. Rabe, A. Zangvil, and Y. Xu, "Structure and Properties of Sylramic" Silicon Carbide Fiber - A Polycrystalline, Stoichiometric $\beta$-SiC Composition," Ceram. Eng. Sci. Proc., 18 [3] 147-157 (1997)

8. G.N. Morscher, Unpublished data.

9. G.N. Morscher, H. M. Yun, J. A. DiCarlo, and L. Thomas-Ogbuji, "Outside Debonding of the BN Interphase in SiC/SiC Composites," submitted to J. Am. Ceram. Soc.

10. J.I. Eldridge, N.P. Bansal, and R.T. Bhatt, "The Evolution of Interfacial Sliding Stresses During Cyclic Phush-In Testing of C-and BN-Coated hi-Nicalon Fiber-Reinforced CMCs" Ceram. Eng. Sci. Proc., 19 [3] 11-18 (1998)

11. G.N. Morscher and J.I. Eldridge, "Constituent Effects on the Stress-Strain Behavior of Woven Melt-Infiltrated SiC Composites," in the Advances in Fracture Research Proceedings of

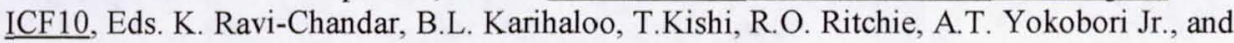
T. Yokobori. Elsevier Science. Honolulu Hawaii, December 2-6, 2001.

12. G.N. Morscher and J. Hurst, "Stress-Rupture and Stress-Relaxation of SiC/SiC Composites at Intermediate Temperature," Ceram. Eng. Sci. Proc., 22 [3] 539-546 (2001) 